\title{
Past Editor Series \\ Prime time to resuscitate clinical medicine and kill diagnostic greed?
}

C Rajasoorya, FRCP (Lond), FRCP (Edin)

ABSTRACT Modern healthcare faces the challenges of rising costs, increasing expectations of patients and changing disease patterns. Physicians practise medicine in an era of easy availability and access to a plethora of modern and sometimes expensive diagnostic aids. The powerful utility of clinical skills cannot be underestimated nor lost. The physician has a powerful platform to encourage the rational use of tests, prevent wasteful overutilisation and ensure that tests do not cause more harm than benefit in physical, emotional or financial terms. Diagnostic skills should not be substituted by diagnostic greed. It is possible to do more for the patient rather than to the patient.

\section{INTRODUCTION}

Many forces have influenced the landscape in which medicine is practised. Modern healthcare faces the challenges of rising costs, increasing expectations and changing disease patterns. The physician may not realise that he has a powerful platform that can influence the delivery of healthcare, an area often subconsciously delegated to or blamed on healthcare administrators, insurance companies, pharmaceutical firms, lawyers, politicians, hospitals and even patients. ${ }^{(1)}$ It was estimated that at least $60 \%$ of healthcare costs are influenced or determined by physicians. ${ }^{(2)}$ More astounding is the knowledge that, at least in the United States, waste alone may account for $30 \%$ of overall healthcare costs. ${ }^{(3)}$ In the era of modern diagnostics, we must not undervalue clinical skills that are sadly dying and in desperate need of resuscitation. Diagnostic tests are necessary, but overutilisation can harm both the sick and the healthy. A clear distinction must be made between what is done to and for the patient.

An inadequate amount of time spent talking to and clinically examining patients is a fundamental flaw in current-day practice, despite the crucial contribution of the former to the effective care of the patient. Concerns have been raised about the increasing global lack of appreciation of bedside clinical skills across the continuum, from medical undergraduates to the teaching faculty..$^{(4-11)}$

Notwithstanding all the advances in evaluation diagnostics, there is still good evidence that history-taking and examination can significantly influence the ability to reach the correct final diagnosis. Hampton et al ${ }^{(12)}$ demonstrated that medical history produced the final diagnosis in a majority of patients, with laboratory investigation providing additive value in only one out of 80 consultations. Sandler, ${ }^{(13)}$ in a two-year study involving outpatients presenting to a district general hospital in the United Kingdom, showed that among patients with chest pain, clinical history produced a diagnosis in $90 \%$ of patients, and routine investigation (mainly chest radiography and electrocardiography) and special tests helped with only $3 \%$ and $6 \%$ of diagnoses, respectively. Peterson et al ${ }^{(14)}$ demonstrated that the correct final diagnosis could be obtained in $76 \%$ of patients presenting to a primary care clinic with a previously undiagnosed condition. Kirch and Schafii compared the accuracy of history-taking and examination with diagnostic imaging, using autopsy studies of 400 patients as the standard. ${ }^{(15)}$ They found that the combination of medical history and physical examination was accurate in $70 \%$ of the cases, whereas diagnostic imaging produced a correct diagnosis in only $35 \%$ of cases. Kattah et al ${ }^{(16)}$ suggested that a three-step bedside oculomotor examination is more sensitive than early diffusion-weighted magnetic resonance (MR) imaging in diagnosing stroke in patients presenting with an acute vestibular syndrome.

The reliability of clinical signs, particularly in regard to cardiac and respiratory examination, has been questioned;(17) studies suggested that some commonly taught signs (e.g. tracheal position) have very poor reliability ${ }^{(18)}$ or may be misleading in suggesting an inherent valvular abnormality. ${ }^{(19)}$ This does not negate the function of clinical reasoning and logic of the entire process of history-taking and examination. Experienced clinicians can discern the emphasis they should place on the positive and negative contributions of specific symptom(s) and/or sign(s) when elucidating a diagnosis. However, it is important that doctors and medical students have knowledge of the reliability and limitations of clinical signs. In the formative years of medical education, it is particularly relevant to appreciate (at least in retrospect) why a particular symptom or sign was helpful (or unhelpful).

It has been further suggested that clinical examination not only enables data gathering and information synthesis, but is also a vital ritual between the doctor and patient that helps to foster trust. ${ }^{(9)}$ Clinicians and administrators dealing with complaints from patients will be all too familiar with the commonly heard dissatisfaction of not being listened to or examined adequately. Students and junior doctors can be motivated to observe, 
participate and engage in a holistic approach to diagnostics, in which the attending physician serves as a role model who actively and passively conveys the soft skills of medicine, such as communication and medical ethics.

Despite the importance of bedside teaching in imparting a variety of clinical skills important for the medical profession, its utility is declining from as much as $75 \%$ of all clinical training in the 1960 s to current estimates of $8 \%-19 \% .{ }^{(20)}$ Changing demographics of patient admissions to hospitals, increasing workload and the meteoric increase in imaging and laboratory testing has, in part, been blamed for this decline. In an era of electronic medical records, technology allows voluminous data to be read before patient encounters. However, this brings with it attendant problems, including errors in previous documentation (due to 'cut-and-paste' technology) and the introduction of a new observer bias, where judgement is made even before patient encounters. The patient is short-changed of a fresh look at the presenting problem and has to deal with the associated potential bias of the past, which is almost a Procrustean crime. ${ }^{(21,22)}$ While the contribution of medical history or electronic data cannot be ignored, despite their shortcomings, it would be helpful to enhance technology such that past medical records are used in conjunction with clinical methods, rather than replacing them.

The easy availability of diagnostic aids and lack of confidence in clinical assessment, as well as the pressure to reduce the time required and need to rule out rare presentations, has contributed to an over-reliance on investigations. Pappworth ${ }^{(23)}$ cautioned against the entity of 'diagnostic greed' when he suggested, "Overwhelming evidence is not essential for correct diagnosis, and the absence of some expected symptom or sign often does not invalidate an otherwise reasonable diagnosis". Medical students are taught that 'common things occur commonly' but are highly influenced by the 'just to rule out' mentality in their careers. The latter presumably occurs in an increased medicolegal climate and is a shortcut solution to performing a detailed clinical assessment and overcoming uncertainty. A domino or cascading effect arises when one 'ruling-out' unravels new issues that were never the concern of either the patient or attending physician. Throughout the entire process, patients are shunted between various specialists and the primary issue of concern or presenting problem becomes camouflaged. The consequences of finding something we never intended to look for has tremendous downstream implications and unwritten costs for both the patient and healthcare system. There is a tremendous resource, emotional (continual mental anguish and apprehension) and financial impact on the individual who is undergoing testing. Over the years, the emphasis on the fact that rare things can be common but common things are never rare has somehow been lost.

In the current practice, it is much easier and less timeconsuming to request computed tomography (CT) than it is to convince a patient that he does not need a CT. Doctors pressured for time yield to such requests. The ability to see detailed visual images as well as its easy availability has led many doctors (as well as patients and their relatives) to subscribe to the belief that such sophisticated imaging techniques are faultless, precise and final, leading to increasing demand. ${ }^{(24)}$ It is not uncommon to see CT scans permeating the clinical evaluation algorithm for headaches, giddiness and head injuries, even if these are simple and uncomplicated with obvious causes or manifestations. Even in the absence of abnormalities, reporting is performed such that it perpetuates doubts, resulting in the unnecessary recommendation of further diagnostic imaging studies. Similarly, CT abdomen and pelvic scans are so routinely utilised, even in clear-cut cases of acute appendicitis, that surgeons seem to doubt their own clinical ability and acumen for diagnosis, inadvertently causing more harm to their patients. ${ }^{(25-27)}$ It is common for a patient presenting with a typical urinary tract infection to undergo CT of the abdomen and pelvis. A simple case of Bell's palsy or drowsiness is evaluated with a CT scan, followed by MR imaging, while a simple blood sugar level test may be forgotten.

Published data on the risk of cancer (small but real) due to radiation exposure on $\mathrm{CT}$ is increasingly available. Of particular concern is the epidemiological data indicating that this risk is not too far from the lifetime risk estimates for atomic bomb survivors. ${ }^{(28)}$ The question naturally arises of whether patients are informed of these risks and about contrast-induced nephropathy, particularly when $\mathrm{CT}$ is performed due to pressure or for frivolous reasons.

While highlighting that medical imaging has yielded unarguable benefits to patients, the American Board of Radiology Foundation ${ }^{(29)}$ conceded that there were concerns about the overutilisation of medical imaging (defined as imaging procedures that circumstances indicate are unlikely to improve patient outcome). They identified factors that included payment mechanisms, financial incentives, practice behaviour of referring physicians, self-referral, defensive medicine, missed educational opportunities when inappropriate procedures are requested, patient expectations and duplicate imaging studies as reasons for the overutilisation of imaging.

The over-investigative behaviour is not only peculiar to diagnostic imaging. One only needs to scrutinise investigations requested for patients presenting at our hospitals and clinics. Full blood count, renal panel and cardiac enzymes are often routinely requested. Furthermore, thyroid and liver function tests, and calcium panels have subtly made their entry into these screening panels for most patients, even in the emergency department. To simplify electronic ordering, 'laboratory panels and packages' have been introduced in recent years, further contributing to wastage (unwanted but 'free' tests).

Female patients of reproductive age who present with symptoms remotely related to the abdomen or pelvis routinely undergo urine or blood pregnancy tests without any attention to or mention of menstrual history, or value placed on patient history or physician suspicion. This recommendation comes, in part, from studies suggesting the need for a routine pregnancy test on all female patients admitted to hospital. ${ }^{(30-32)}$ Others have also argued that a pregnancy test should not be routine. ${ }^{(33,34)}$ In the milieu of the practice of medicine, where trust and consent are emphasised in a doctor-patient relationship, the patient is often not informed that a pregnancy test is being performed at 
her own cost, particularly if the patient has little chance of being pregnant. Do doctors give thought to how offended a patient may be if she knew a pregnancy test was being performed without her consent or adequate explanation?

Some measures that may influence the indiscriminate use of tests include limiting more expensive orders to senior specialists, performing regular audits (with financial accountability), including cost reflections in order-menus and enforcing accountability by consultants who supervise juniors. Painful as they may seem, these measures provide an avenue for selfregulation in current practice and prevent abuse. This practice is not new and parallels can be seen in antibiotic stewardship programmes implemented across hospitals both in Singapore and internationally. Another bold initiative that can be considered is one that is similar to that proposed by the American Board of Internal Medicine in its 'Choosing Wisely' campaign, which influences specialist societies, scholarly journal articles and mainstream media to encourage patient-physician conversations that question waste and overuse in healthcare. ${ }^{(35)}$ Topics of these conversations include best evidence, the prevention of duplicate tests, assessment of harm and the necessity of tests.

Perhaps it is timely to instil the reflexive mentality, for anyone requesting for an investigation (particularly the more expensive or invasive tests) to ask three critical questions: (a) Am I likely to get new or additional information that clinical history and examination cannot tell me?; (b) Is the investigation likely to change the management?; and (c) How is the investigation going to influence the outcome in this particular patient?

As clinicians, we hold the responsibility, power and professionalism to practise good medicine. We cannot pretend that we are not responsible (at least in part) for the rising healthcare costs and wasteful overutilisation of diagnostic tests. We owe it to our patients to choose wisely and prevent abuse of the never-ending technological advances in medicine. Diagnostic skills should never be substituted by diagnostic greed.

The Past Editor Series is a collection of invited articles written by former SMJ Editors, who are respected medical practitioners in their respective field of expertise.

\section{REFERENCES}

1. Tilburt JC, Wynia MK, Sheeler RD, et al. Views of US physicians about controlling health care costs. JAMA 2013; 310:380-8.

2. Agrawal S, Taitsman J, Cassel C. Educating physicians about responsible management of finite resources. JAMA 2013; 309:1115-6.

3. Berwick DM, Hackbarth AD. Eliminating waste in US health care. JAMA 2012; 307:1513-6.

4. Mangione S. Cardiac auscultatory skills of physicians-in-training: a comparison of three English-speaking countries. Am J Med 2001; 110:210-6.

5. Holmboe E. Faculty and the observation of trainees' clinical skills: problems and opportunities. Acad Med 2004; 79:16-22.

6. Vukanovic-Criley JM, Criley S, Warde CM, et al. Competency in cardiac examination skills in medical students, trainees, physicians, and faculty: a multicenter study. Arch Intern Med 2006; 166:610-6.
7. Fred HL. Hyposkillia: deficiency of clinical skills. Tex Heart Inst J 2005; 32:255-7.

8. Grais IM. Bedside skills: a 50-year personal retrospective. Tex Heart Inst J 2010; 37:629-32.

9. Verghese A, Horwitz RI. In praise of the physical examination - it provides reason and ritual. BMJ 2009; 339:1385-6.

10. Elder A, Chi J, Ozdalga E, Kugler J, Verghese A. A piece of my mind. The road back to the bedside. JAMA 2013; 310:799-800.

11. Elder AT, Verghese A. Bedside matters - putting the patient at the centre of teaching and learning. J R Coll Physicians Edinb 2015; 45:186-7.

12. Hampton JR, Harrison MJ, Mitchell JR, Prichard JS, Seymour C. Relative contributions of history-taking, physical examination, and laboratory investigation to diagnosis and management of medical outpatients. BMJ $1975 ; 2: 486-9$.

13. Sandler G. The importance of the history in the medical clinic and the cost of unnecessary tests. Am Heart J 1980; 100(6 Pt 1):928-31.

14. Peterson MC, Holbrook JH, Von Hales D, Smith NL, Staker LV. Contributions of the history, physical examination, and laboratory investigation in making medical diagnoses. West J Med 1992; 156:163-5.

15. Kirch W, Schafii C. Misdiagnosis at a university hospital in 4 medical eras. Medicine (Baltimore) 1996; 75:29-40.

16. Kattah JC, Talkad AV, Wang DZ, Hsieh YH, Newman-Toker DE. HINTS to diagnose stroke in the acute vestibular syndrome: three-step bedside oculomotor examination more sensitive than early MRI diffusion-weighted imaging. Stroke 2009; 40:3504-10.

17. Spence D. Bad medicine: chest examination. BMJ 2012; 345:e4569.

18. Spiteri MA, Cook DG, Clarke SW. Reliability of eliciting physical signs in examination of the chest. Lancet 1988; 1:873-5.

19. Movahed MR, Ebrahimi R. The prevalence of valvular abnormalities in patients who were referred for echocardiographic examination with a primary diagnosis of "heart murmur". Echocardiography 2007; 24:447-51.

20. Peters $M$, Ten Cate O. Bedside teaching in medical education: a literature review. Perspect Med Educ 2014; 3:76-88

21. Hsu JL, Banerjee D, Kuschner WG. Understanding and identifying bias and confounding in the medical literature. South Med J 2008; 101:1240-5.

22. Baskerville JR. Observer and subject bias: lessons from procrustes. Acad Emerg Med 2010; 17:1032.

23. Pappworth MH. Diagnostic Pitfalls: The Sin of Greed. A Primer of Medicine. London: Butterworths, 1978: 32-3.

24. Larson DB, Johnson LW, Schnell BM, Salisbury SR, Forman HP. National trends in CT use in the emergency department: 1995-2007. Radiology $2011 ; 258: 164-73$

25. Rogers W, Hoffman J, Noori N. Harms of CT scanning prior to surgery for suspected appendicitis. Evid Based Med 2015; 20:3-4.

26. Hong J, Cohen SM, Ekeh AP, et al; Miami Appendicitis Group. A prospective randomized study of clinical assessment versus computed tomography for the diagnosis of acute appendicitis. Surg Infect (Larchmt) 2003; 4:231-9.

27. Rhea JT, Halpern EF, Ptak T, et al. The status of appendiceal CT in an urban medical center 5 years after its introduction: experience with 753 patients. AJR Am J Roentgenol 2005; 184:1802-8.

28. Brenner DJ, Hall EJ. Cancer risks from CT scans: now we have data, what next? Radiology 2012; 265:330-1.

29. Hendee WR, Beck GJ, Borgstede JP, et al. Addressing overutilization in medical imaging. Radiology 2010; 257:240-5.

30. Laubach GE, Wilchins SA. Routine pregnancy test on admission to hospital. Am J Obstet Gynecol 1975; 123:691-4.

31. Köksal O, Ozdemir F, Armağan E, et al. Is routine pregnancy test necessary in women of reproductive age admitted to the emergency department? World J Emerg Med 2013; 4:175-8.

32. Lippmann S, Bordador B, Shaltout T. Detection of unknown early pregnancy. A matter of safety. Postgrad Med 1988; 83:129-31, 135.

33. Minnerop MH, Garra G, Chohan JK, Troxell RM, Singer AJ. Patient history and physician suspicion accurately exclude pregnancy. Am J Emerg Med $2011 ; 29: 212-5$

34. Ramoska EA, Sacchetti AD, Nepp M. Reliability of patient history in determining the possibility of pregnancy. Ann Emerg Med 1989; 18:48-50.

35. The ABIM Foundation. Choosing Wisely [online]. Available at: http://www. choosingwisely.org/about-us/. Accessed March 4, 2016. 